\title{
PRODUÇÃO DE BIOMASSA E COBERTURA DO SOLO PELO CONSÓRCIO DE CROTALÁRIA E MILHETO E SUA INFLUÊNCIA EM PROPRIEDADES FÍSICAS DO SOLO ${ }^{1}$
}

\author{
Karina Mendes Bertolino \\ Giuliana Rayane Barbosa Duarte \\ Gustavo Maldini Penna de Valadares e Vasconcelos \\ Élberis Pereira Botrel \\ Fábio Aurélio Dias Martins
}

\begin{abstract}
RESUMO
O objetivo neste trabalho foi avaliar a cobertura do solo proporcionada pela crotalária e milheto consorciados em diferentes proporções, bem como seus efeitos na qualidade física do solo. A instalação do experimento obedeceu ao delineamento em blocos casualizados. Os tratamentos foram constituídos de crotalária (Crotalaria spectabilis) (CR) e milheto (Pennisetum glaucum L. ) (MI) consorciados em diferentes proporções de semeadura, totalizando seis tratamentos: $100 \%$ CR (crotalária solteira); $80 \% \mathrm{CR}+20 \% \mathrm{MI} ; 60 \% \mathrm{CR}+40 \% \mathrm{MI} ; 40 \% \mathrm{CR}+60 \% \mathrm{MI}$; $20 \% \mathrm{CR}+80 \% \mathrm{MI} ; 100 \% \mathrm{MI}$ (milheto solteiro), com quatro repetições. As variáveis avaliadas foram a biomassa seca aos 118 dias após a semeadura, a porcentagem de cobertura do solo e umidade do solo aos 30, 60, 90 e 120 dias após o manejo das plantas, a resistência a penetração até $40 \mathrm{~cm}$ e densidade do solo na camada de 0-10. Aos 118 dias após a semeadura, a crotalária, o milheto e seus consórcios produziram quantidade de biomassa seca suficiente para promover a cobertura do solo de em média $77 \%$ até os 120 dias após o manejo das plantas, contudo não foram capazes de promover diferenças nos atributos físicos do solo.
\end{abstract}

Palavras-chave: Física do solo. Palhada. Sistema de plantas de cobertura.

BIOMASS PRODUCTION AND SOIL COVERAGE BY THE CROTALARY AND MILLETTE CONSORTIUM AND ITS INFLUENCE ON PHYSICAL PROPERTIES

\begin{abstract}
The aim of this work was to evaluate the soil cover provided by crotalaria and millet intercropped in different proportions, as well as their effects on the physical quality of the soil. The installation of the experiment followed the randomized block design. The treatments consisted of crotalary (Crotalaria spectabilis) (CR) and millet (Pennisetum glaucum L.) (MI) intercropped in different sowing proportions, totaling 6 treatments: $100 \% \mathrm{CR}$ (single crotalary); $80 \% \mathrm{CR}+20 \% \mathrm{MI} ; 60 \% \mathrm{CR}+40 \% \mathrm{MI} ; 40 \% \mathrm{CR}+60 \% \mathrm{MI} ; 20 \% \mathrm{CR}+80 \% \mathrm{MI} ; 100 \% \mathrm{MI}$ (single millet), with 4 repetitions. The variables evaluated were dry biomass at 118 days after sowing, the percentage of soil cover and soil moisture at 30,60, 90 and 120 days after plant

\footnotetext{
${ }^{1}$ Como citar este artigo: BERTOLINO, K. M. et al. Produção de biomassa e cobertura do solo pelo consórcio de crotalária e milheto e sua influência em propriedades físicas dos solo. ForScience, Formiga, v. 9, n. 2, e00931, jul./dez. 2021. DOI: 10.29069/forscience.2021v9n2.e931.

${ }^{2}$ Autor para correspondência: Karina Mendes Bertolino, e-mail: karina.bertolino@yahoo.com.br
} 
management, the resistance to penetration up to $40 \mathrm{~cm}$ and soil density in the $0-10$ layer. At 118 days after sowing the crotalary, the millet and their intercropping produced enough dry biomass to promote an average $77 \%$ soil cover until 120 days after plant management, however, they were unable to promote differences in the physical attributes of the soil.

Keywords: Soil physics. Straw. Cover plants system.

\section{INTRODUÇÃO}

A redução da cobertura superficial e da matéria orgânica decorrente do cultivo intensivo causa a degradação dos solos, resultando em compactação, erosão e diminuição da capacidade produtiva (FREITAS et al., 2017). A compactação causa o aumento da resistência a penetração (RP), diminuição da porosidade, afetando a disponibilidade de água e nutrientes (PRADO; ROQUE; SOUZA, 2002), além de aumentar a densidade do solo. A RP e a densidade são atributos relacionados, os quais são afetados pela textura e umidade do solo e influenciam diretamente no desenvolvimento e crescimento das raízes e parte aérea das plantas (BOTTEGA et al., 2011). Assim, uma das maneiras de mitigar o problema de degradação dos solos seria a utilização de plantas que sejam capazes de superar as restrições dos solos e recuperar sua qualidade quando submetido a distintos sistemas de manejo (ARGENTON et al., 2005).

O uso de diferentes espécies de plantas de cobertura pode ser adotado no planejamento de recuperação de áreas fisicamente degradadas, especialmente aquelas plantas com sistemas radiculares distintos. Em muitos casos, a consorciação entre duas ou mais espécies são capazes de melhorar a estrutura de solos fisicamente degradados (TEIXEIRA; PAULETTO; SILVA, 2003). As plantas de cobertura produzem fitomassa e, com isso, protegem o solo reduzindo a evaporação da água, o impacto direto das gotas de chuva, o escoamento superficial e, por consequência, reduz os processos erosivos, possibilitando melhora na estruturação dos atributos químicos e físicos do solo (CARDOSO et al., 2013). Outra vantagem é o surgimento de bioporos pela atividade radicular e da mesofauna do solo, além da penetração de raízes em camadas mais compactadas e o potencial de adição de carbono ao solo, proporcionando melhora da qualidade física que favorece o crescimento de outras culturas (ANDRADE; STONE; SILVEIRA, 2009).

O milheto (Pennisetum glaucum L.) é uma gramínea adaptada a condições adversas; é resistente ao déficit hídrico e proporciona elevada produção de biomassa seca (FRANÇA; MIYAGI, 2012). É uma planta rústica, de crescimento rápido, possui adaptação a solos de baixa fertilidade e, em função das características do seu sistema radicular, tem a capacidade de romper camadas compactadas do solo (GUIMARÃES et al., 2013) apresentando, assim, crescimento 
uniforme e sistema radicular que pode atingir grandes profundidades (FRANÇA, MIYAGI, 2012).

Já a crotalária (Crotalaria spectabilis), é uma leguminosa anual com desenvolvimento inicial lento, possui vantagens como redução da multiplicação de nematóides, proporciona satisfatório acúmulo de fitomassa e grande capacidade de incorporação de nitrogênio $(\mathrm{N})$ ao sistema por meio da fixação biológica (PACHECO et al., 2015). É uma planta arbustiva que tem um sistema radicular pivotante, que assim como as raízes do milheto, pode romper as camadas mais compactadas do solo (BARRETO; FERNANDES, 2001).

O consórcio entre gramíneas e leguminosas e seus efeitos na qualidade física do solo tem sido estudo por alguns autores. Para Shinkai et al. (2020), o uso de espécies leguminosas juntamente com espécies gramíneas pode promover ação conjunta para a melhoria nas propriedades do solo. Carvalho et al. (2013) relataram que o consórcio entre gramíneas e leguminosas trazem benefícios, devido aos sistemas radiculares distintos. Devido a isso, esse consórcio favorece a estrutura física do solo e a produção de matéria seca com relação C/N intermediária, permitindo, assim, menor taxa de decomposição dos resíduos culturais e promovendo uma cobertura do solo mais prolongada.

Diante do exposto, o objetivo do trabalho foi avaliar a cobertura do solo proporcionada pela Crotalaria spectabilis e Pennisetum glaucum L. consorciados em diferentes proporções, bem como seu efeito na qualidade física do solo.

\section{MATERIAL E MÉTODOS}

O experimento foi instalado na área experimental do Departamento de Agricultura (DAG) da Universidade Federal de Lavras (UFLA), em Lavras/MG, com coordenadas geográficas de $21^{\circ} 14^{\prime} \mathrm{S}$ e $45^{\circ} 00^{`} \mathrm{~W}$ e altitude média de $920 \mathrm{~m}$. O clima da região é classificado como temperado úmido (Cwa) de acordo com Köppen, com inverno seco e chuvas predominantes no verão, com precipitação média anual de $1530 \mathrm{~mm}$ e temperatura média anual de 19,4 ${ }^{\circ} \mathrm{C}$ (BRASIL, 1992; DANTAS; CARVALHO; FERREIRA, 2007). O solo da região é classificado como Latossolo Vermelho Distroférrico Típico (LVDT) (EMBRAPA, 1999). A área utilizada se encontrava há três anos em pousio. Os dados de precipitação pluvial e temperaturas ocorridas no período de outubro de 2017 a outubro de 2018 estão representadas na Figura 1. 


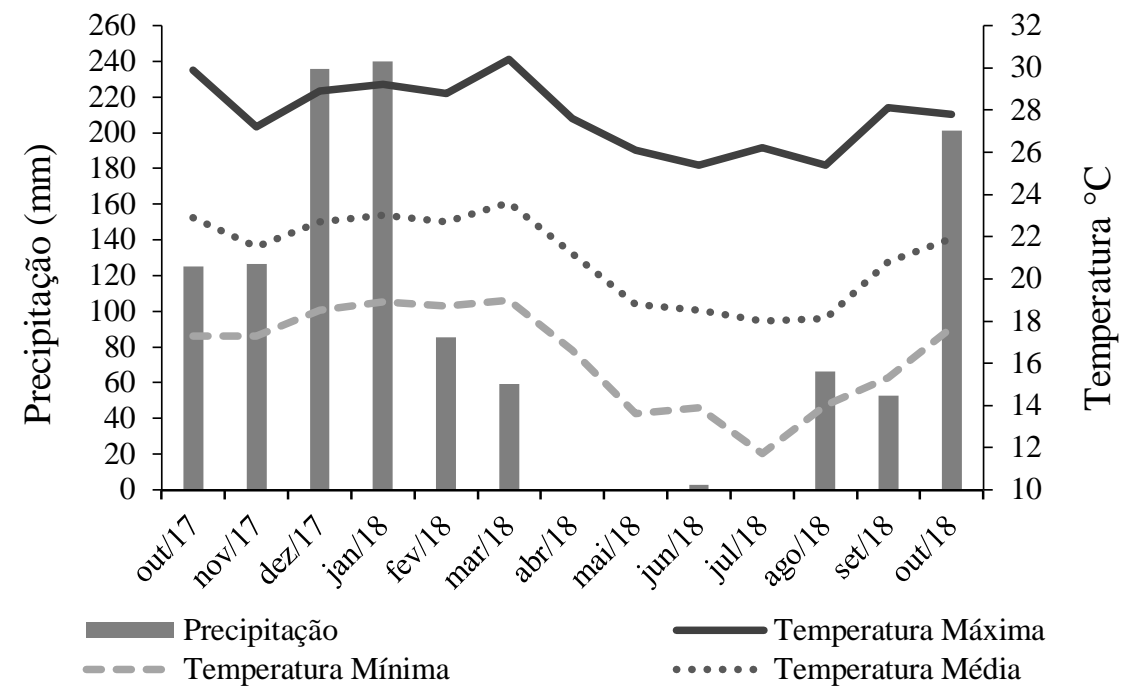

Figura 1 - Precipitação pluvial $(\mathrm{mm})$ total e temperaturas $\left({ }^{\circ} \mathrm{C}\right)$ mínimas, médias e máximas no período de outubro de 2017 a outubro de 2018 em Lavras/MG

A análise química e granulométrica do solo anterior a instalação do experimento apresentou as seguintes características na camada de 0 - 0,20 m: $\mathrm{pH} \mathrm{H}_{2} 0: 6,85 ; \mathrm{Ca}^{2+}: 1,1 \mathrm{cmol}$ $\mathrm{dm}^{-3}, \mathrm{Mg}^{2+}: 0,4 \mathrm{cmol} \mathrm{dm}^{-3} ; \mathrm{Al}^{3+}: 0,1 \mathrm{cmol} \mathrm{dm}^{-3} ; \mathrm{H}+\mathrm{Al}: 2,7 \mathrm{cmol} \mathrm{dm}^{-3}$; Soma de Bases: $1,8 \mathrm{cmol}$ $\mathrm{dm}^{-3}$; CTC efetiva (t): 1,9 $\mathrm{cmol} \mathrm{dm}^{-3}$; CTC a pH 7 (T): 4,5 $\mathrm{cmol} \mathrm{dm}^{-3}$; P (Melhic-1): 12,5 mg $\mathrm{dm}^{-3} ; \mathrm{K}^{+}:$110,8 mg dm${ }^{-3}$; Saturação por Bases: 39,6\%; Matéria Orgânica: 2,06 dag kg-1; Argila: 37 dag kg-1; Silte:13 dag kg-1; Areia: 50 dag kg-1.

O delineamento experimental utilizado foi o de blocos casualizados (DBC), constituído de seis proporções de plantas de cobertura consorciadas entre si, totalizando seis tratamentos com quatro repetições. A parcela experimental foi formada por 10 linhas de $4 \mathrm{~m}$ de comprimento, espaçadas de $0,30 \mathrm{~m}$ entre si, totalizando $12,0 \mathrm{~m}^{2}$ com uma área útil de 7,2 $\mathrm{m}^{2}$.

O experimento foi instalado em campo em novembro de 2017. Para o preparo do solo, foi realizada uma aração e duas gradagens até $0,20 \mathrm{~m}$ de profundidade e a calagem utilizando 1,31 $\mathrm{t} \mathrm{ha}^{-1}$ em acordo com as recomendações de Sousa e Lobato (2004). Na sequência, procedeu-se a abertura dos sulcos de forma mecanizada para delimitação das parcelas.

As plantas de cobertura foram semeadas simultaneamente e manualmente no sulco de plantio, utilizando-se para a crotalária (CR) (Crotalaria spectabilis) cultivar "comum" a quantidade de $20 \mathrm{~kg} \mathrm{ha}^{-1}$ de sementes para a proporção de $100 \%$ e, para o milheto (MI) (Pennisetum glaucum) cultivar BRS1501, $25 \mathrm{~kg} \mathrm{ha}^{-1}$ de sementes para a proporção de $100 \%$, ambos da Piraí Sementes. Posteriormente foi calculada e semeada a quantidade de semente de acordo com os demais tratamentos constituídos com diferentes proporções de milheto e 
crotalária: $100 \%$ CR; $80 \%$ CR+ 20\% MI; $60 \%$ CR + 40\% MI; 40\% CR + 60\% MI; 20\% CR + $80 \% \mathrm{MI} ; 100 \% \mathrm{MI}$.

Na ocasião da semeadura, não foram realizadas adubações. Aos 35 dias após o semeio, foi realizada a capina manual para o controle de plantas daninhas.

A determinação da biomassa seca das plantas de cobertura foi realizada aos 118 dias após a semeadura, na ocasião crotalária se encontrava no início do florescimento e o milheto próximo à maturidade fisiológica. A biomassa seca foi obtida a partir da colheita de três metros de linha de plantas em duas linhas centrais da parcela experimental. As plantas foram pesadas em campo e, em seguida, retirou-se uma amostra de 500 gramas e o restante foi devolvido ao local. As amostras foram secas em estufa de circulação forçada de ar a $65{ }^{\circ} \mathrm{C}$, até atingirem peso constante.

Aos 120 dias após a semeadura, as plantas de cobertura foram manejadas rente ao solo com roçadora costal, posteriormente, a porcentagem de cobertura do solo foi avaliada aos 30 , 60, 90 e 120 dias após o manejo, utilizando-se um quadro de madeira de 0,50 metros de cada lado, com rede de barbantes a cada 0,05 metros, em que foi observada a cobertura do solo proporcionada pelas diferentes proporções de plantas de cobertura utilizadas, de acordo com a metodologia utilizada por Sodré-Filho et al. (2004).

Para a obtenção da umidade gravimétrica do solo, foram coletadas amostras deformadas de solo na camada de $0-10 \mathrm{~cm}$ em três pontos aleatórios dentro da área útil de cada parcela, as quais foram analisadas separadamente e compuseram uma média por parcela por época. As coletas foram realizadas aos 30, 60, 90 e 120 dias após a roçagem das plantas, no momento da avaliação da taxa de cobertura do solo. No laboratório, as amostras foram pesadas e, em seguida, secas em estufa de circulação forçada de ar a $105{ }^{\circ} \mathrm{C}$ por 24 horas e, logo após a secagem, pesadas novamente.

A análise de resistência à penetração do solo (RP) foi realizada aos 131 dias após o manejo das plantas de cobertura com roçadeira (DAM), uma determinação por parcela nas entrelinhas das linhas de plantio. Utilizou-se para este procedimento um penetrômetro de impacto modelo IAA/Planalsucar-Stolf. A penetração foi medida após cada impacto e penetração da haste no solo (MOLIN; DIAS; CARBONERA, 2012) até a profundidade de 40 cm. Os dados obtidos foram processados em uma planilha eletrônica desenvolvida por Stolf (2011). Simultaneamente a análise de RP, com auxílio de um trado, foram coletadas amostras deformadas de solo nas profundidades de $0-10 ; 10-20 ; 20-30 ; 30-40 \mathrm{~cm}$ de profundidade em um ponto por parcela para a determinação da umidade do solo. 
A avaliação da densidade superficial do solo foi realizada aos 180 DAM. Foram coletadas nas camadas de 0-10 cm amostras indeformadas de solo em anéis volumétricos de altura e $10 \mathrm{~cm}$ de diâmetro. As amostras foram secas em estufa com circulação forçada de ar a $105^{\circ} \mathrm{C}$ durante 48 horas e pesadas após a secagem.

Os dados obtidos de biomassa seca, resistência à penetração, umidade da resistência e a penetração foram submetidos a análise de variância (Teste F) e, quando significativos a médias dos tratamentos foram comparadas pelo teste de Tukey a 5\%. Já os dados obtidos de porcentagem de cobertura do solo e umidade foram submetidos à análise de variância (Teste F), o que permitiu avaliar o efeito das proporções de semeio de plantas de cobertura/tratamentos (parcelas) e dos períodos de avaliação/época (subparcelas) bem como a interação entre estes fatores. Quando significativas, as médias das épocas foram submetidas a análise de regressão e as médias dos tratamentos comparadas pelo teste de Tukey a 5\% de significância utilizando o programa estatístico Sisvar versão 5.6 (FERREIRA, 2011).

\section{RESULTADOS E DISCUSSÃO}

A produtividade de biomassa seca total (MS) não diferiu estatisticamente entre MI, CR e consórcios MI + CR (valor p=0,77) (Tabela 1$)$.

Tabela 1 - Média da produtividade de biomassa seca do milheto (MI), crotalária (CR) e consórcios (MI + CR) nos diferentes tratamentos

\begin{tabular}{cc}
\hline Tratamento & Biomassa Seca kg ha $^{-1}$ \\
\hline $100 \% \mathrm{CR}$ & 7.421 \\
$80 \% \mathrm{CR}+20 \% \mathrm{MI}$ & 7.679 \\
$60 \% \mathrm{CR}+40 \% \mathrm{MI}$ & 7.486 \\
$40 \% \mathrm{CR}+60 \% \mathrm{MI}$ & 6.560 \\
$20 \% \mathrm{CR}+80 \% \mathrm{MI}$ & 7.083 \\
$100 \% \mathrm{MI}$ & 5.900 \\
\hline
\end{tabular}

*Biomassa seca avaliada aos 118 dias após a semeadura

A biomassa seca total obtida neste estudo para os tratamentos com monocultivo de CR foi inferior e a de MI superior (Tabela 1) ao alcançado por outros autores como Castro et al. (2017) que encontraram em seu trabalho para o MI e CR em monocultivo uma biomassa seca de, respectivamente $8.000 \mathrm{~kg} \mathrm{ha}^{-1}$ e $2.300 \mathrm{~kg} \mathrm{ha}^{-1}$ em diferente época de cultivo e aos 90 dias após plantio na região central de MG. No consórcio entre MI + CR na proporção de $50 \%$ de cada espécie, a biomassa seca total obtida no referido trabalho foi de $5.900 \mathrm{~kg} \mathrm{ha}^{-1}$, também inferior à obtida no presente trabalho. 
Os resultados obtidos para porcentagem de cobertura do solo nas diferentes épocas de avaliação estão representados na Figura 2 e Tabela 2. Não foi verificada interação significativa para porcentagem de cobertura do solo e épocas de avaliação (valor p=0,47). Entretanto foi significativo para época de avaliação de forma isolada (valor p menor que 0,01).

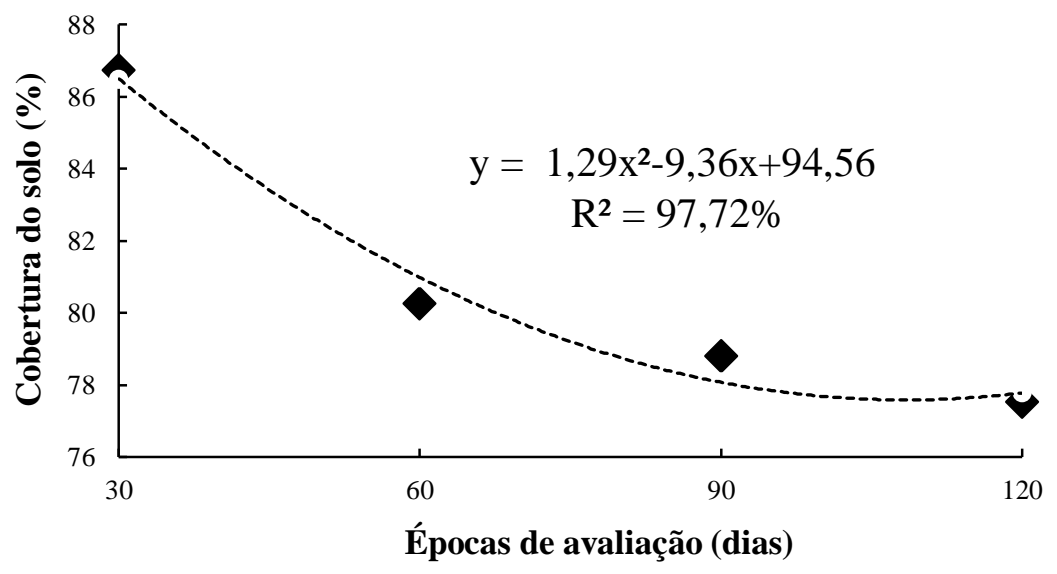

Figura 2 - Médias das porcentagens de cobertura do solo promovida pela palhada remanescente dos resíduos culturais dos tratamentos constituídos de crotalária (CR), milheto (MI) e consórcios de crotalária e milheto

(CR+MI) ao longo dos 30, 60, 90 e 120 dias após a roçagem das plantas

Tabela 2 - Médias das porcentagens de cobertura do solo em cada tratamento constituídos de crotalária (CR), milheto (MI) e consórcios de crotalária e milheto $(\mathrm{CR}+\mathrm{MI})$

\begin{tabular}{cc}
\hline Tratamento & Cobertura do Solo (\%) \\
\hline $100 \%$ CR & 79,12 \\
$80 \%$ CR+20\% MI & 70,58 \\
$60 \%$ CR+40\% MI & 83,01 \\
$40 \%$ CR+60\% MI & 82,65 \\
$20 \%$ CR+80\% MI & 87,82 \\
$100 \%$ MI & 81,79 \\
\hline
\end{tabular}

*Valores médios de porcentagem de cobertura do solo obtidas das avaliações realizadas aos 30, 60, 90 e 120 dias após a roçagem das plantas

Embora os tratamentos foram constituídos de gramíneas e leguminosas e o consórcio com proporções diferentes destas plantas, na Figura 2, observa-se que os tratamentos tiveram o mesmo comportamento em relação à cobertura do solo ao longo das épocas de estudo, ou seja, não houve diferença na porcentagem de cobertura do solo entre os tratamentos dentro de uma mesma época de avaliação. De acordo com Souza et al. (2014), o tempo de permanência da cobertura do solo e sua eficiência na conservação do mesmo, é determinada pela taxa de decomposição dos resíduos culturais, fator que é regulado pela relação $\mathrm{C} / \mathrm{N}$ de cada espécie. Porém de acordo com Giacomini et al. (2003), o consórcio entre plantas de cobertura como gramíneas e leguminosas proporcionou ao solo uma massa seca com relação $\mathrm{C} / \mathrm{N}$ intermediária possibilitando uma menor taxa de decomposição dos resíduos e garantindo a cobertura do solo 
por mais tempo, além da sincronia da demanda e fornecimento de nitrogênio para os cultivos principais. Assim, no presente estudo, observa-se que, embora exista diferença na composição química do material vegetal utilizado, não foi possível verificar diferenças na porcentagem de cobertura do solo entre as épocas estudadas quando comparados os diferentes tratamentos.

Já para as médias da porcentagem de cobertura do solo obtida para os tratamentos (Tabela 2), foram superiores a obtidas por Casto et al. (2017) que relataram para o MI, CR e consórcio $(\mathrm{CR}+\mathrm{MI})$ valores de 50,2\%, 81,9\% e 50,2\% respectivamente, após o manejo que foi realizado aos 90 dias após a semeadura em um Latossolo Vermelho Distrófico na região central de MG. Para Alvarenga et al. (2001), para uma boa porcentagem de cobertura do solo no sistema de plantio direto, é necessária uma quantidade de $6 \mathrm{t} \mathrm{ha}^{-1}$ de biomassa seca, assim, embora não tenha verificado diferença significativa para biomassa seca entre os tratamentos avaliados, apenas o tratamento 100\% MI não está acima da quantidade mínima necessária para o sistema.

Embora possa observar uma acentuada queda na taxa de cobertura do solo aos 30, $90 \mathrm{e}$ 120 dias, o solo ainda contava com $77 \%$ de sua superfície coberta pela palhada. Dessa forma, o manejo das plantas de cobertura deve ser levado em consideração quando se visa permanência da palhada e menor decomposição de seus resíduos. Segundo Bortoluzzi e Eltz (2000), em manejos em que se realizam a trituração da palha acarretando em elevação da área superficial do material e submetendo essa palha a maior contato com o solo, observa-se acentuada decomposição dos resíduos vegetais e redução da cobertura sobre o solo. Portanto, as temperaturas mais baixas, precipitação pluviométrica em menores volumes (Figura 1) durante o período de avaliação da porcentagem de cobertura do solo e, o método de manejo das plantas de cobertura em que os resíduos foram submetidos nesse ensaio (roçadora costal), podem ter contribuído para uma menor decomposição dos resíduos e, consequentemente, uma satisfatória taxa de cobertura proporcionada ao solo por um maior período de tempo. Segundo Alvarenga et al. (2001), para o sistema de plantio direto é necessária uma taxa de cobertura do solo mínima de 50\%. Temos, portanto, taxas de cobertura do solo provenientes dos tratamentos estudados estão acima do mínimo necessário para o referido sistema de plantio (Tabela 2).

Não houve interação significativa entre os tratamentos (proporções de semeadura) e épocas de avaliação ( $\mathrm{p}$ valor $=0,07$ ) para a umidade do solo, entretanto foi significativo para essas variáveis de forma isolada (valor p para tratamento $=0,01$ e para época menor que 0,01 ) (Tabela 3 e Figura 3). 
Tabela 3 - Médias da umidade do solo para a camada de 0-10 cm nos diferentes tratamentos constituídos de milheto (MI) e crotalária (CR) consórcios de crotalária e milheto $(\mathrm{CR}+\mathrm{MI})$

\begin{tabular}{cc}
\hline Tratamentos & Umidade (\%) \\
\hline $100 \%$ CR & $11,24 \mathrm{ab}$ \\
$80 \% \mathrm{CR}+20 \%$ MI & $11,29 \mathrm{ab}$ \\
$60 \% \mathrm{CR}+40 \%$ MI & $10,95 \mathrm{~b}$ \\
$40 \% \mathrm{CR}+60 \%$ MI & $11,17 \mathrm{~b}$ \\
$20 \% \mathrm{CR}+80 \%$ MI & $10,96 \mathrm{~b}$ \\
$100 \%$ MI & $12,36 \mathrm{a}$ \\
\hline
\end{tabular}

Médias seguidas pela mesma letra não diferem entre si pelo teste de Tukey a 5\%. * Valores médios de umidade obtidos das avaliações realizadas aos 30,60, 90 e 120 dias após a roçagem das plantas

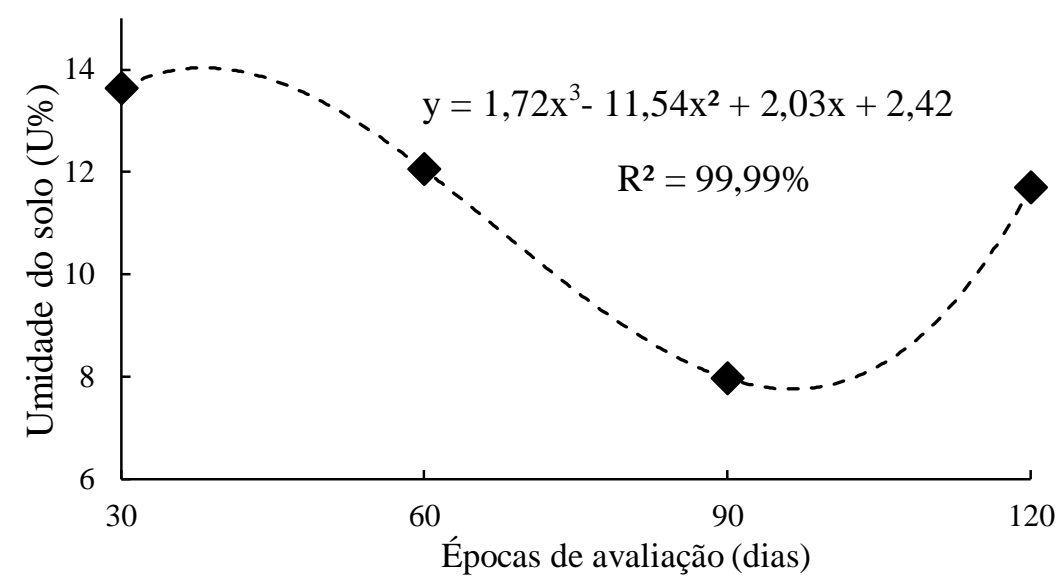

Figura 3 - Médias da umidade presente no solo na camada de $0-10 \mathrm{~cm}$ nos tratamentos constituídos de crotalária (CR), milheto (MI) e consórcios de crotalária e milheto (CR + MI) ao longo dos 30, 60, 90 e 120 dias após a roçagem das plantas (épocas de avaliação)

O menor teor de umidade $(7,97 \%)$ observada aos 90 dias após o manejo (Figura 3) pode estar relacionado com os baixos índices de precipitação pluviométricas ocorridas no local. De acordo com Borges et al. (2014), a umidade do perfil do solo está diretamente relacionada à ocorrência da precipitação que aconteceu anteriormente e a sua permanência nas coberturas presentes na superfície do solo. Dessa forma, o maior teor de umidade do solo observado para o tratamento sob $100 \%$ MI pode estar relacionado às características inerentes à planta. Segundo a Embrapa (2018), o milheto é uma planta que possui o sistema radicular abundante e profundo e em alguns casos pode atingir mais de dois metros de profundidade. Assim, essas raízes quando em decomposição, criam canalículos que aumentam a infiltração de água no solo (BRANCALIÃO et al., 2014) e, consequentemente, maior umidade. A cobertura do solo, por sua vez, contribui para melhor aproveitamento da água da chuva (BORGES et al., 2014), reduz a velocidade do vento sobre a superfície do solo, minimizando a perda de água por evaporação (KLEIN; KLEIN, 2014). 
Não foram verificadas diferenças significativas para resistência à penetração (Figura 4) e para a umidade do solo (Figura 5) nas profundidades avaliadas dentre os tratamentos estudados.

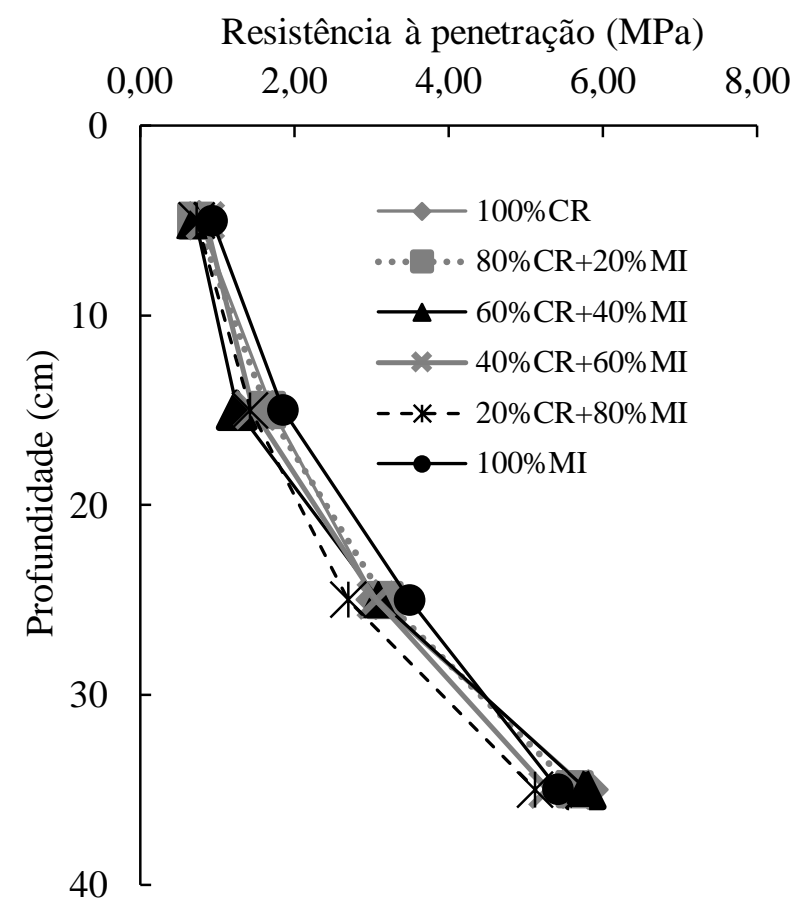

Figura 4 - Resistência à penetração (MPa) nas diferentes profundidades do solo para os tratamentos avaliados

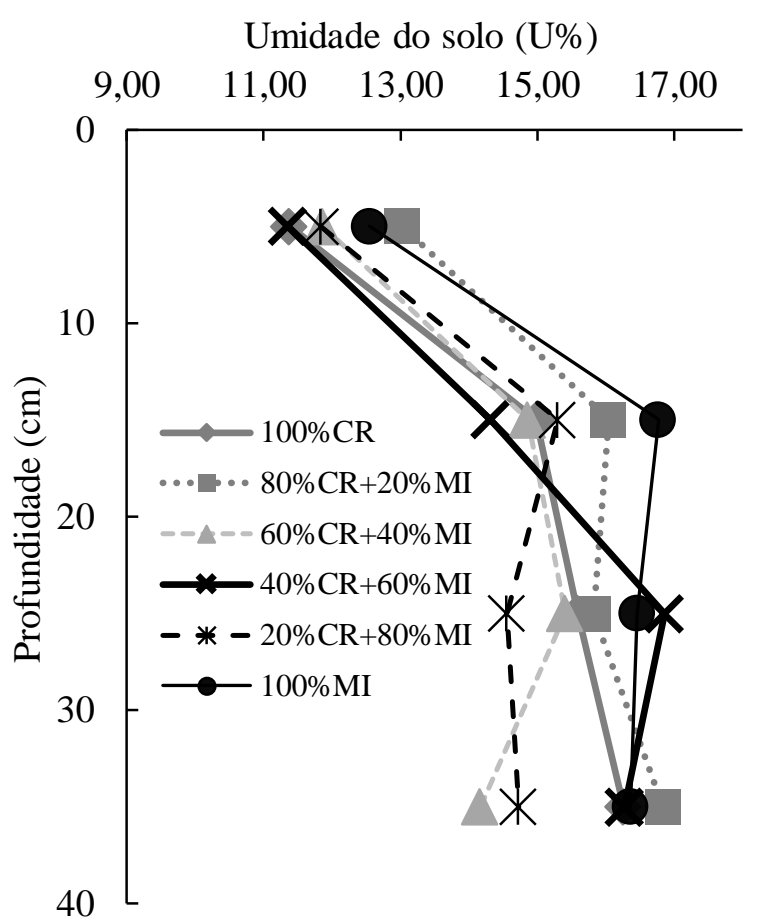

Figura 5 - Umidade do solo nas diferentes profundidades do solo para os tratamentos avaliados

Assis et al. (2014), avaliando a resistência à penetração de Argissolo Amarelo, também não verificaram diferenças significativas entre solos cultivados com plantas de cobertura até a profundidade de $30 \mathrm{~cm}$. Os autores atribuíram o resultado ao pouco tempo de condução do experimento, em que as avaliações foram realizadas após o período vegetativo das plantas que durou cinco meses. Já para Cardoso et al. (2013), analisando o potencial de espécies de plantas de cobertura como crotalária, feijão-de-porco (Canavalia ensiformis (L.) DC) e milheto para o condicionamento químico e físico do solo, observaram que, em seu trabalho,em avaliações realizadas 27 dias após o corte das plantas de cobertura (130 dias após a semeadura) que foram cultivadas em um Argissolo Vermelho Distrófico no município de Lavras/MG, de maneira geral, as plantas de cobertura reduziram a resistência à penetração do solo na camada até 25 $\mathrm{cm}$. Os autores relatam ainda que tal efeito por ter sido ocasionado em razão do desenvolvimento do sistema radicular ao longo do ciclo da cultura e posterior decomposição das raízes. 
Na camada superficial do solo, obtiveram-se valores de 0,72 $\mathrm{MPa}$ a 0,87 $\mathrm{MPa}$ e 1,26 MPa a 1,86 MPa, respectivamente para as camadas de 0-10 $\mathrm{cm}$ e 10-20 cm. Assis et al. (2014) evidenciaram para estas mesmas profundidades em um Argissolo Amarelo após cinco meses de cultivo para milheto (1,14 e 2,43 MPa, respectivamente para as camadas de 0-10 e 10-20 cm) e crotalária (1,30 e 3,54 MPa, respectivamente para as camadas de 0-10 e 10-20 cm) e classificaram os valores de resistência a penetração desses tratamentos como altos. Já Mazurana et al. (2011) observaram que os sistemas de preparo do solo interferiram em atributos como densidade, porosidade, infiltração de água e resistência à penetração. Os autores concluíram ainda que a resistência à penetração aumentou com a profundidade, porém reduziu com o aumento da mobilização do solo. Assim, os resultados de resistência à penetração para as camadas superficiais encontradas neste trabalho podem estar relacionados com o preparo do solo realizado anteriormente na área, provavelmente eficiente até $20 \mathrm{~cm}$ de profundidade.

Nas camadas de 20-30 e 30-40 cm, foi possível observar um aumento acentuado da resistência à penetração para todos os tratamentos (Figura 4). Tal comportamento pode ser explicado pelo fato de o preparo de solo realizado na área não ter alcançado além da profundidade de $20 \mathrm{~cm}$. Para alguns autores como Assis et al. (2009), a resistência à penetração está diretamente relacionada com a sua umidade, logo, à medida que diminui o teor de água em um solo, ocorre o aumento significativo da resistência à penetração. Contudo, tal relação não foi observada para este trabalho, em que se verificaram maiores valores de RP, sobretudo na camada de 30-40 cm, na qual foram encontradas maiores umidades. Neste caso, conforme a Figura 5, o teor umidade do solo não influenciou nos valores de resistência à penetração das camadas avaliadas.

Os valores mais altos de resistência à penetração encontrados em subsuperfície para este trabalho podem ser explicados pelo histórico da área, uma vez que ela foi cultivada para experimentação agrícola em muitos anos anteriores ao pousio e antes da implantação desse experimento. Cherubin et al. (2011) verificaram resultado semelhante, quando obtiveram aumento da resistência à penetração em camadas mais profundas de solo $(20,30,40 \mathrm{~cm})$. Os autores relacionaram os maiores valores de RP a uma camada de impedimento mecânico que pode estar relacionado ao "pé-de-arado" ou "pé-de-grade", efeito causado pelo preparo de solo no sistema convencional de cultivo. Para Alves e Suzuki (2004), o "pé-de-grade" ou "pé-dearado" é causado pelo trabalho do implemento utilizado para o preparo do solo em uma mesma profundidade repetidamente, geralmente em condição de umidade inadequada.

Canarache (1990), citado por Gomes Júnior et al. (2016), classificou os limites de resistência à penetração em muito baixos, quando menores ou igual a 1,0 MPa, baixos quando 
entre 1,1 e 2,5 $\mathrm{MPa}$, de 2,6 a 5,0 MPa médios, entre 5,1 e 10,0 MPa altos, de 10,1 a 15,0 MPa muito altos e, extremamente altos quando maiores de $15 \mathrm{MPa}$. É possível considerar, portanto, que, para os valores baixos e muitos baixos não existe limitação para o crescimento de raízes, para médios há algumas limitações, em altos existem limitações e para os muitos altos e extremamente altos não é possível o crescimento de raízes. Portanto, podemos inferir pelos valores obtidos neste trabalho que a resistência para as camadas 0-10 e 10-20 cm é considerada muito baixa e baixa e, para 20-30 e 30-40 cm altos.

Segundo Tormena e Roloff (1996), valores de resistência maiores que $2 \mathrm{MPa}$ são restritivos ao crescimento de raízes da maioria das espécies cultivadas. Já Girardello et al. (2014) observaram que o valor crítico de resistência à penetração em Latossolo Vermelho foi de 3,0 MPa reduzindo a produtividade da soja (Glycine Max L.) em 10\% e, a partir desse valor, pequenos incrementos no valor de resistência à penetração podem causar acentuado decréscimo de produtividade, chegando a 38\% de perdas da oleaginosa em solos com valores de 5,0 MPa. Para Rosolen et al. (1999), uma resistência à penetração de 1,3 MPa reduz o crescimento das raízes adventícias do milho (Zea mays L.). Assim, pode-se inferir que os valores encontrados neste trabalho para a camada de 0-10 e 10-20 cm estão dentro dos valores críticos para a maioria das culturas, contudo, as raízes dessas plantas encontrariam restrições a partir da profundidade de $20 \mathrm{~cm}$. Reinert et al. (2008) evidenciaram em seu trabalho sobre limites de densidades de solo para o crescimento de raízes de plantas de cobertura em um Argissolo Vermelho, que o crescimento das raízes das plantas tende a ocorrer em camadas de solo onde existe menor resistência à penetração, o que irá compensar, em parte, o volume total de solo explorado pelo sistema radicular, contudo, este acúmulo de raízes em camadas mais superficiais tende a causar prejuízos em épocas de déficit hídrico.

Não foram verificadas diferenças significativas para a densidade do solo dentre os tratamentos avaliados ( $\mathrm{p}$ valor $=0,33)($ Tabela 4$)$.

Tabela 4 - Médias da densidade do solo na camada de 0-10 cm nos tratamentos constituídos de crotalária (CR), milheto (MI) e consórcios de crotalária e milheto $(\mathrm{CR}+\mathrm{MI})$

\begin{tabular}{cc}
\hline Tratamento & Densidade $\mathbf{g ~ c m}^{\mathbf{- 3}}$ \\
\hline $100 \% \mathrm{CR}$ & 1,09 \\
$80 \% \mathrm{CR}+20 \% \mathrm{MI}$ & 1,10 \\
$60 \% \mathrm{CR}+40 \% \mathrm{MI}$ & 1,11 \\
$40 \% \mathrm{CR}+60 \% \mathrm{MI}$ & 1,14 \\
$20 \% \mathrm{CR}+80 \% \mathrm{MI}$ & 1,11 \\
$100 \% \mathrm{MI}$ & 1,12 \\
\hline
\end{tabular}


Assis et al. (2014) observaram diferentes valores de densidade do solo na camada de 0$10 \mathrm{~cm}$ para áreas cultivadas com mucuna (Mucuna deringiana) $\left(1,53 \mathrm{~g} \mathrm{~cm}^{-3}\right)$, milheto $(1,56 \mathrm{~g}$ $\mathrm{cm}^{-3}$ ), crotalária (Crotalaria spectabilis) $\left(1,81 \mathrm{~g} \mathrm{~cm}^{-3}\right)$ e feijão de porco (Canavalia ensiformis) $\left(1,56 \mathrm{~g} \mathrm{~cm}^{-3}\right)$, de Argissolo Vermelho Amarelo de textura muito argiloso, cultivado há dez anos sob cultivo convencional, contudo sem diferenças significativas entre os tratamentos. Já Sulzback et al. (2017) obtiveram resultados próximos para camada de 0-10 cm em uma área de Latossolo Vermelho Distroférrico de textura argilosa, utilizando plantas de cobertura como milheto (1,04 $\left.\mathrm{g} \mathrm{cm}^{-3}\right)$, guandu-anão (Cajanus cajan) $\left(0,87 \mathrm{~g} \mathrm{~cm}^{-3}\right)$, crotalária juncea (Crotalaria juncea L.) (1,11 g cm-3), crotalária spectabilis $\left(1,08 \mathrm{~g} \mathrm{~cm}^{-3}\right)$ e mucuna preta (Mucuna pruriens) $\left(1,01 \mathrm{~g} \mathrm{~cm}^{-3}\right)$, semeadas em sistema de plantio direto, porém, os autores verificaram diferenças entre os tratamentos avaliados atribuindo ao guandú-anão o potencial de diminuir os efeitos da compactação dos solos.

Para Torres e Saraiva (1999), a variação da densidade de solos argilosos vai desde 1,00 $\mathrm{g} \mathrm{cm}^{-3}$ sob condições naturais e altos teores de matéria orgânica, até $1,45 \mathrm{~g} \mathrm{~cm}^{-3} \mathrm{em}$ solos sob más condições de manejo e compactados. Já a densidade de solos arenosos varia em média de

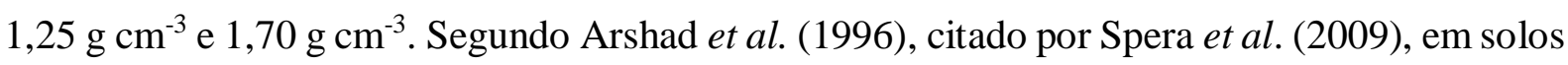
argilosos, a densidade do solo acima de $1,40 \mathrm{~g} \mathrm{~m}^{-3}$ é restritiva ao crescimento radicular e, consequentemente, ao rendimento de grãos dos cultivos. Contudo, Reinert et al. (2008), em seu trabalho sobre limites críticos de densidade do solo para o crescimento de raízes de plantas de cobertura em um Argissolo Vermelho de textura média, no qual avaliaram o solo sob cultivo de crotalária juncea, guandu-anão, feijão de porco e mucuna cinza (Mucuna pruriens (L.)), concluíram que o crescimento normal das plantas de cobertura ocorre até o limite de densidade do solo de $1,75 \mathrm{~g} \mathrm{~cm}^{-3}$. De 1,75 a $1,85 \mathrm{~g} \mathrm{~cm}^{-3}$, há restrição e deformações na morfologia das raízes de grau médio e, acima de $1,85 \mathrm{~g} \mathrm{~cm}^{-3}$, as deformações são mais acentuadas, com grande engrossamento, desvios no crescimento vertical e acúmulo nas camadas mais superficiais.

Os valores de densidade do solo encontrados para o Latossolo Vermelho Distroférrico típico de textura argilosa do presente trabalho estão dentro dos limites estabelecidos por Torres e Saraiva (1999), Arshad et al. (1996) e Reinert (2008). No entanto, segundo Bicalho (2011), a densidade do solo é uma propriedade variável dependente da estrutura e da compactação do solo, sendo muito influenciada pelo material constituinte, pelos sistemas de uso e tipo de cobertura vegetal. Sendo assim, os valores de densidade do solo podem ser extremamente variáveis, podendo ocorrer diferentes densidades no perfil de solos com mesma textura. Porém, para Reinert et al. (2008), deve-se levar em consideração que a densidade crítica é dependente 
principalmente da classe textural do solo. Por se tratar do primeiro ano de adoção do sistema em estudo, a CR, o MI e o consórcio constituído de MI + CR, não promoveram diferenças marcantes em atributos físicos do solo como resistência à penetração e densidade do solo. Entretanto, melhores resultados podem ser obtidos na mesma área com o avanço do tempo de adoção do sistema.

\section{CONCLUSÃO}

Aos 118 dias após a semeadura, a crotalária, o milheto e seus consórcios produzem em média $7 \mathrm{t} \mathrm{ha}^{-1}$ de biomassa seca e garante uma cobertura do solo de em média $77 \%$ até os 120 dias após a roçagem das plantas, no município de Lavras/MG.

As plantas de cobertura estudadas e seus consórcios em diferentes proporções não promoveram diferenças na resistência à penetração até a profundidade de $40 \mathrm{~cm}$ e na densidade do solo até a profundidade de $10 \mathrm{~cm}$, em um Latossolo Vermelho Distroférrico típico de textura argilosa, para o primeiro ano de implantação dessas culturas sob uma aração e duas gradagens.

\section{REFERÊNCIAS}

ALVARENGA, R. C. et al. Plantas de cobertura do solo para sistema de plantio direto. Informe Agropecuário, Belo Horizonte, v. 22, n. 208, p. 25-36, 2001.

ALVES, M. C.; SUZUKI, L. E. A. S. Influência de diferentes sistemas de manejo do solo na recuperação de suas propriedades físicas. Revista Acta Scientiarum. Agronomy, Maringá, v. 26, n. 1, p. 27-34, 2004.

ANDRADE, R. S.; STONE, L. F.; SILVEIRA, P. M. Cultura de cobertura e qualidade física de um latossolo em plantio direto. Revista Brasileira de Engenharia Agrícola e Ambiental, Campina Grande, v. 13, n. 4, p. 411-418, 2009.

ARGENTON, J. et al. Comportamento de atributos relacionados com a forma da estrutura de latossolo vermelho sob sistemas de preparo e plantas de cobertura. Revista Brasileira de Ciência do Solo, Viçosa, v. 29, n. 3, p. 425-435, 2005.

ARSHAD, M.A.; LOWERY, B.; GROSSMANN, B. Physical tests for monitoring soil quality. In: DORAN, J.W.; JONES, A.J. (Ed.). Methods for assessing soil quality. Madison: Soil Science Society of America, 1996, p.123-141 (SSSA Special publication, 49).

ASSIS, R. F. et al. Avaliação da resistência à penetração em diferentes solos com variação do teor de água. Revista Engenharia Agrícola, Jaboticabal, v. 29, n. 4, p. 558-568, 2009. 
ASSIS, E. B. et al. Resistência à penetração em argissolo vermelho-amarelo sob pousio e diferentes culturas de cobertura. Enciclopédia Biosfera, Goiânia, v. 10, n. 19, p. 1668-1677, 2014.

BARRETO, A. C.; FERNANDES, M. F. Recomendações técnicas para o uso da adubação verde em solos de tabuleiros costeiros. Circular Técnica 19, Aracajú, dez. 2001.

BICALHO, I. M. Um estudo da densidade do solo em diferentes sistemas de uso e manejo. Enciclopédia Biosfera, Goiânia, v. 7, n. 12, p. 1-9, 2011.

BORGES, T. K. S. et al. Influência de práticas conservacionista na umidade do solo e no cultivo do milho (Zea mays L.) em semiárido nordestino. Revista Brasileira de Ciência do Solo, Viçosa, v. 38, n. 6, p. 1862-1873, 2014.

BORTOLUZZI, E. C.; ELTZ, F. L. F. Efeito do manejo mecânico da palhada de aveia sobre a cobertura, temperatura, teor de água no solo e emergência da soja em sistema de plantio direto. Revista Brasileira de Ciência do Solo, Viçosa, v. 24, n. 2, p. 449-457, 2000.

BOTTEGA, L. E. et al. Variabilidade espacial da resistência à penetração de um latossolo vermelho distroférrico. Revista Brasileira de Ciências Agrárias, Recife, v. 6, n. 2, p. 331336, 2011.

BRANCALIÃO, S. R. et al. Sistema radicular do milheto e ciclagem de cálcio em nitossolo vermelho cultivado em sistema de plantio direto. Revista Científica Eletrônica Uniseb, Rio Claro, n. 3, p. 227-237, 2014.

BRASIL. Ministério da Agricultura. Departamento Nacional de Meteorologia. Normas climatológicas. 1961-1990. Brasília, 1992.

CANARACHE, A. Penetrometer: a generalized semi-empirical model estimating soil resistance to penetration. Soil Tillage Research, Amsterdam, v. 16, n. 1-2, p. 51-70, 1990.

CARDOSO, D, P. et al. Espécies de plantas de cobertura no recondicionamento químico e físico do solo. Revista Brasileira de Ciências Agrárias, Recife, v. 8, n. 3, p. 375-382, 2013.

CARVALHO, W. P. et al. Desempenho agronômico de plantas de cobertura usadas na proteção do solo no período de pousio. Pesquisa Agropecuária Brasileira, Brasília, v. 45, n. 2, p. 157-166, 2013.

CASTRO, G. F. et al. Plantas de cobertura em sucessão ao milho para silagem em condições de cerrado. Journal of Bioenergy and Food Science, Viçosa, v. 4, n. 1, p. 37-49, 2017.

CHERUBIN, M. R. et al. Variabilidade da resistência a penetração do solo em função da dimensão da malha amostral. Revista Plantio Direto, Passo Fundo, v. 125, n. 5, p. 1-9, 2011.

DANTAS, A. A. A.; CARVALHO, L. G. de; FERREIRA, E. Classificação e tendência climática em Lavras, MG. Ciência e Agrotecnologia, Lavras, v. 31, n. 6, p. 1862-1866, 2007.

EMPRESA BRASILEIRA DE PESQUISA AGROPECUÁRIA. Sistema brasileiro de classificação de solos. Brasília, 1999. 
EMPRESA BRASILEIRA DE PESQUISA AGROPECUÁRIA. Sistema de produção Embrapa. O cultivo do milheto. Brasília, 2018. Disponível em:

https://www.spo.cnptia.embrapa.br/conteudo?p_p_id=conteudoportlet_WAR_sistemasdeprod ucaolf6_1ga1ceportlet $\& p \_p \_$lifecycle $=0 \& p \_p \_$state $=$normal $\& p \_p \_$mode $=v i e w \& p \_p \_c o l i d=$ column-1\&p_p_col_count=1\&p_r_p_-76293187_sistemaProducaoId=8101\&p_r_p_996514994 topicoId=1309. Acesso em: 7 dez. 2018.

FERREIRA, D. F. Sisvar: a computer statistical analysis system. Ciência e Agrotecnologia, Lavras, v. 35, n. 6, p. 1039-1042, 2011.

FRANÇA, A. F. S.; MIYAGI, E. S. Alternativas alimentares para animais no cerradomilheto: apenas uma solução proteica? Revista UFG, Goiânia, n. 13, p. 42-47, 2012.

FREITAS, L. et al. Indicadores da qualidade química e física do solo sob diferentes sistemas de manejo. Revista Unimar Ciências, Marília, v. 26, p. 8-25, 2017.

GIACOMINI, S. J. et al. Matéria seca, relação C/N e acúmulo de nitrogênio, fósforo e potássio em misturas de plantas de cobertura de solo. Revista Brasileira de Ciência do Solo, Viçosa, v. 27, n. 2, p. 325-334, 2003.

GIRARDELLO, V. C. et al. Resistência à penetração, eficiência de escarificadores mecânicos e produtividade da soja em Latossolo argiloso manejado sob plantio direto de longa duração. Revista Brasileira de Ciência do Solo, Viçosa, v. 38, n. 4, p. 1234-1244, 2014.

GOMES JUNIOR, D. G. et al. Soil physical quality of brazilian crop management systems evaluated with aid of penetrometer. Journal of Agricultural Science, v. 8, n. 6, p. 120-128, 2016.

GUIMARÃES, C. V. et al. Desempenho de cultivares e híbridos de milheto em solo submetido a compactação. Revista Brasileira de Engenharia Agrícola e Ambiental, Campina Grande, v. 17, n. 11, p. 1188-1194, 2013.

KLEIN, C.; KLEIN, V. A. Influência do manejo do solo na infiltração de água. Revista Monografias Ambientais, Santa Maria, v. 13, n. 5, p. 3915-3925, 2014.

MAZURANA, M. et al. Sistemas de preparo de solo: alterações na estrutura do solo: rendimento das culturas. Revista Brasileira de Ciência do Solo, Viçosa, v. 35, n. 4, p. 1197 1206, 2011.

MOLIN, J. P.; DIAS, C. T. D. S.; CARBONERA, L. Estudos com penetrometria: novos equipamentos e amostragem correta. Revista Brasileira de Engenharia Agrícola e Ambiental, Campina Grande, v. 16, n. 5, p. 584-590, 2012.

PACHECO, L. P. et al. Influência da densidade do solo em atributos da parte aérea e sistema radicular de crotalária. Revista Pesquisa Agropecuária Tropical, Goiânia, v. 45, n. 4, p. 464-472, 2015.

PRADO, M. P.; ROQUE, C. R.; SOUZA, Z. S. Sistemas de preparo e resistência à penetração e densidade de um latossolo vermelho eutrófico em cultivo intensivo e pousio. Pesquisa

Agropecuária Brasileira, Brasília, v. 37, n. 12, p. 1795-1801, 2002. 
REINERT, D. J. et al. Limites críticos de densidade do solo para o crescimento de raízes de plantas de cobertura em argissolo vermelho. Revista Brasileira de Ciência do Solo, Viçosa, v. 32, n. 5, p.1 805-1816, 2008.

ROSOLÉM, C. A. et al. Crescimento radicular de plântulas de milho afetado pela resistência do solo à penetração. Pesquisa Agropecuária Brasileira, Brasília, v. 34, n. 5, p. 821-828, 1999.

SHINKAI, A. L. et al. Características produtivas da soja sobre sistemas integrados de produção do consórcio de gramíneas e leguminosas em modo de colheita do milho. Brazilian Journal of Development, Curitiba, v. 6, n. 6, p. 37700-37705, 2020.

SODRÉ-FILHO, J. et al. Fitomassa e cobertura do solo de culturas de sucessão ao milho na região do cerrado. Pesquisa Agropecuária Brasileira, Brasília, v. 39, n. 4, p. 327-334, 2004.

SOUSA, D. M. G. de; LOBATO, E. Calagem e adubação para culturas anuais e semiperenes. In: SOUSA, D. M. G. de; LOBATO, E. (Ed.). Cerrado: correção do solo e adubação. 2. ed. Brasília: Embrapa Informação Tecnológica, 2004. p. 283-315.

SOUZA, A. P. et al. Taxas de decomposição de resíduos vegetais submetidos a lâminas de irrigação. Revista Irriga, Botucatu, v. 19, n. 3, p. 512-526, 2014.

SPERA, S. T. et al. Atributos físicos do solo em sistemas de manejo de solo e de rotação de culturas. Revista Bragatia, Campinas, v. 68, n. 4, p. 1079-1093, 2009.

STOLF, R. Penetrômetro de impacto stolf: programa de manipulação de dados em Excel. São Carlos: UFSCar, 2011.

SULZBACH, L. G. et al. Implicações de espécies de cobertura em parâmetros físicos-hídricos de um latossolo argiloso e no rendimento de grãos de soja. Revista Acta Iguazu, Cascavel, v. 6, n. 5, p. 280-286, 2017.

TEIXEIRA, C. F. A.; PAULETTO, E. A.; SILVA, J. B. Resistência à penetração de um argissolo amarelo distrófico típico sob diferentes sistemas de produção em plantio direto. Ciência Rural, Santa Maria, v. 33, n. 6, p. 1165-1167, 2003.

TORMENA, C. A.; ROLOFF, G. Dinâmica da resistência à penetração de um solo sob plantio direto. Revista Brasileira de Ciência do Solo, Viçosa, v. 20, n. 2, p. 333-339, 1996. TORRES, E.; SARAIVA, O. Camadas de impedimento mecânico do solo em sistemas agrícolas com a soja. Circular Técnica 23, Embrapa Soja, Londrina, out. 1999.

\section{DADOS DOS AUTORES}

\section{Karina Mendes Bertolino}

E-mail: karina.bertolino@yahoo.com.br

Curriculum Lattes: http://lattes.cnpq.br/4879536941988300

Doutoranda e mestrado em Fitotecnia pela Universidade Federal de Lavras e graduação em Engenharia Agronômica e Bacharelado Interdisciplinar em Biossistemas pela Universidade Federal de São João del Rei. 
Giuliana Rayane Barbosa Duarte

E-mail: giuliana_duarte@yahoo.com.br

Curriculum Lattes: http://lattes.cnpq.br/4063782409496857

Graduação em Agronomia pela Universidade Federal de Lavras e Facultad de Ciencias Agrarias Y Forestales - Universidad Nacional de La Plata. Atualmente é servidora pública (Técnico em Agropecuária) na Universidade Federal de Lavras. Tem experiência na área de Melhoramento Genético de Olerícolas, com ênfase em alface e feijão vagem.

\section{Gustavo Maldini Penna de Valadares e Vasconcelos}

E-mail: gustavomaldini@hotmail.com

Curriculum Lattes: http://lattes.cnpq.br/8568026446196324

Mestrando em Fitotecnia na Universidade Federal de Lavras e graduação em Engenharia Agronômica e Bacharelado Interdisciplinar em Biossistemas pela Universidade Federal de São João del-Rei.

\section{Élberis Pereira Botrel}

E-mail: elberis@ufla.br

Curriculum Lattes: http://lattes.cnpq.br/6996830597561413

Doutorado, mestrado e graduação em Agronomia pela Universidade Federal de Lavras. Atualmente é Professor Associado II na Universidade Federal de Lavras. Exerceu as funções de Chefe do Departamento de Agricultura, Pró-Reitor de Assuntos Estudantis e Comunitários, Chefe de Gabinete, Prefeito Universitário e Assessor de Comunicação Social. Tem experiência na área de Agronomia, com ênfase em manejo e tratos culturais, atuando principalmente nos seguintes temas: plantio direto, adubação verde, plantas de cobertura, manejo de resíduos, agroenergia, café, soja, mandioca e olerícolas.

\section{Fábio Aurélio Dias Martins}

E-mail: fabioaureliod@gmail.com

Curriculum Lattes: http://lattes.cnpq.br/6408397494330059

Doutorado e mestrado em Fitotecnia pela Universidade Federal de Lavras e graduação em Engenharia Agronômica pela Universidade Federal de Lavras. Atua como pesquisador na Empresa de Pesquisa Agropecuária do Estado de Minas Gerais e com sistemas de produção de grãos, arroz, feijão, milho, soja, trigo e sorgo, manejo da fixação biológica do feijoeiro comum e outras leguminosas, além de biofortificação agronômica. 